\title{
Redução de custos por meio da reorganização do modelo de trabalho da secretaria municipal de saúde de um município do $A B C$ de São Paulo
}

\author{
Cristiana Nunes CARVALHO ${ }^{(1)}$ \\ Ricardo Eugênio Mariani BURDELIS ${ }^{(1)}$ \\ Sabrina Martins Pedrosa CAFOLLA ${ }^{(1)}$
}

${ }^{(1)}$ Universidade Federal de São Paulo - UNIFESP, São Paulo, SP, Brasil.

Recebido: 28 jan 2019 Aceito: 10 fev 2019

Autor de correspondência: carvalhocn@live.com

Conflito de interesses: Os autores declaram não haver nenhum interesse profissional ou pessoal que possa gerar conflito de interesses em relação a este manuscrito.

\section{Resumo}

O Sistema Único de Saúde - SUS é resultado de um movimento contra hegemônico e desejo da população em relação ao acesso à saúde. O cenário econômico e social da criação do SUS possui uma importante diferença dos demais países que conquistaram modelos universais de saúde pública, ou seja, tratam-se de países com contexto político e social favoráveis à cidadania e com disponibilidade de recursos. Sendo assim, desde a criação do sistema de saúde brasileiro um dos dilemas identificados é em relação ao seu financiamento. Neste âmbito, o aumento constante do percentual da população dependente de atendimento no sistema público de saúde devido ao cenário socioeconômico atual, o aumento da expectativa de vida, o não funcionamento efetivo das regiões de saúde e, cada vez mais presente, a dificuldade nas questões orçamentário-financeiras municipais são fatores que desafiam a realização da gestão de recursos financeiros escassos. Adicionalmente, alguns municípios brasileiros possuem mais um fator dificultador: a gestão mista, ou seja, uma gestão com contratação de trabalhadores pela gestão pública e por organizações sociais de direito privado contratadas. Esse ponto pode ser considerado crítico naqueles casos em que os contratos não foram revisados adequadamente e, portanto, não são aderentes às reais necessidades. Diante dos desafios supramencionados, aos profissionais que assumem um papel de gestão nas Secretarias de Saúde surgem indagações no que tange a como enfrentá-los, manter uma boa relação com os profissionais de saúde já ingressos nos locais de trabalho e como criar um modelo de trabalho que melhore a percepção do usuário em relação ao serviço. Nesse sentido, ao assumir o papel de gestor em saúde no âmbito municipal, é extremamente importante compreender a saúde financeira de sua Pasta e de seu município, o escopo e a estrutura dos contratos em andamento e as políticas públicas vigentes, visando desenvolver uma gestão eficiente, transparente e coesa. Objetivo: desenvolver um modelo de trabalho, de forma colegiada, que atenda às políticas públicas de saúde e leis atuais, bem como tenha por visão atender às necessidades dos usuários, embasado na realização de uma avaliação econômica dos cenários atual e futuro, por meio da compreensão do contexto municipal e da estrutura gerida pela Secretaria de Saúde. Método: revisão de literatura e pesquisa documental, em um município da 
região do Grande $A B C$ de São Paulo, para compreensão do quadro de trabalhadores versus cenário atual. Realização de reuniões em três etapas com os gestores de cada área da Secretaria de Saúde, e suas equipes, durante os meses de março e abril de 2018. Cabe destacar que as reuniões sempre contaram com a presença do Secretário de Saúde, um representante da área Administrativa e um representante da área de Gestão do Trabalho, se possível os Secretários Adjuntos, além da equipe convidada para o encontro. A primeira etapa consistiu no levantamento do cenário atual (quadro de recursos humanos com o tipo de contratação - pública ou por meio da organização social de direito privado, mapeamento dos macroprocessos de trabalho, das necessidades apontadas pela equipe e pelos usuários, discussão dos pontos críticos e das políticas públicas de saúde vigentes naquele contexto). Na segunda etapa foi realizada a apresentação de uma proposta de modelo de trabalho para aquela área. Por fim, a terceira etapa foi a validação do produto. Após a conclusão do diagnóstico situacional de todas as áreas e das demais etapas supracitadas, foi realizada a definição colegiada de uma proposta de modelo de trabalho futuro. Resultados: para atendimento dos usuários com qualidade, de forma transparente e aderente às políticas públicas de saúde, necessidades foram identificadas. A proposta de trabalho desenvolvida consiste na construção de um novo modelo de trabalho, com melhor aproveitamento do contrato com a organização social, alocação adequada dos recursos humanos atuais (incluindo a revisão dos cargos necessários para execução dos macroprocessos de trabalho identificados, e seus desdobramentos), além da contratação de novos profissionais. Sendo assim, a proposta de reorganização obteve como resultado um aumento de mais de 200 trabalhadores e redução de custos em $\mathrm{R} \$ 554.275,25$. Considerando a implementação da proposta, a depender da aprovação de outras instâncias da municipalidade, outros resultados são previstos como: a melhoria no funcionamento da Rede de Atenção à Saúde e da percepção do usuário, além do aumento de repasses federais, considerando a adequação às políticas públicas vigentes. Considerações finais: essa experiência permitiu evidenciar, que assim como é amplamente declarado na literatura, há 30 anos o subfinanciamento do sistema de saúde é uma dificuldade para os gestores. Isso refuta a importância do seu preparo profissional, da compreensão do contexto regional e sua disponibilidade para realização de uma gestão horizontalizada e participativa. Por meio de análises fundamentadas e decisões colegiadas foi possível redesenhar o modelo de trabalho e revisar os contratos para que sejam aderentes às leis e à economicidade. Além disso, tal avaliação permitiu a definição de premissas e, portanto, a definição de metas para o alcance de resultados também no âmbito qualitativo como mecanismos de transparência, investimento no fortalecimento da Atenção Primária, na Educação Permanente em Saúde e no funcionamento em rede.

Descritores: Gestão em Saúde; Organização e Administração; Orçamentos; Sistema Único de Saúde. 